\title{
KOMIKSY, KRÓLIKI I KATANY. USAGI YOJIMBO I JAPONIA Z OKRESU EDO
}

W roku, w którym Ronald Reagan po raz drugi wygrał wybory prezydenckie w Stanach Zjednoczonych, na łamach drugiego numeru „Albedo Anthropomorphics”, wydanego własnym nakładem przez Steve’a Gallacciego, ukazał się pierwszy komiks autorstwa Stana Sakaiego z Usagim Miyamoto w roli głównej ${ }^{1}$. W Polsce pierwszy przekład Usagiego Yojimbo wydano na poczatku lat dwutysięcznych. Tytułowy bohater to królik ronin, którego przygody zabierają czytelnika w podróż do Japonii z okresu Edo (XVII-XIX wiek).

Ze względu na antropomorfizm głównej postaci Usagi Yojimbo może zostać zaliczony do nurtu komisów niezależnych, takich jak Teenage Mutant Ninja Turtles, Cerebrus Aardvark czy Omaha the Cat Dancer, których bohaterami sa antropomorfizowane zwierzęta. To komiksy przygodowe, awanturnicze, a nawet erotyczne, jak w przypadku Omaha the Cat Dancer. Usagi Yojimbo wyróżnia się jednak na ich tle. Choć w komiksach z tej serii dominują elementy przygodowe, to dzieło Stana Sakaiego jest więcej niż tylko rozrywkową lekturą dla młodych czytelników. Wydawana od 1984 r. seria Sakaiego może służyć jako źródło wiedzy z zakresu historii i kultury Kraju Kwitnącej Wiśni, w którym wraz z ustanowieniem szogunatu Tokugawa dokonały się istotne zmiany, m.in. przeniesienie stolicy z Kioto do Edo, izolacja Japonii i kryzys klasy samurajskiej. Sięgając do swoich korzeni, autor wplata liczne ciekawostki na temat zwyczajów i życia codziennego Japończyków z XVII wieku, nadaje w ten sposób komiksowi wymiar historyczno-społeczny.

Niniejszy artykuł jest poświęcony serii Usagi Yojimbo, która stanowi dobre źródło wiedzy dla czytelnika zainteresowanego Japonią oraz dziejami samurajów. Jej znaczenie w kontekście poznania i zrozumienia kultury japońskiej jest niebagatelne, biorąc pod uwagę tematy, które autor porusza, czy staranność, z jaką podchodzi do pracy nad każdą historią. Twórczość Sakaiego jest kolejnym dowodem na niekwestionowana już pozycję komiksu jako wartościowego środka artystycznego wyrazu, jak również znakomitego narzędzia o charakterze edukacyjnym.

1 Stan Sakai stosuje szyk japoński przy antroponimach (najpierw nazwisko, potem imię). W tym artykule zastosowano konwencję europejską (imię plus nazwisko). 


\section{5 lat Usagiego Yojimbo. Inspiracje i kontynuacje}

W Historii Japonii Kenneth G. Henshall pisze: „Wpływ, jaki Japonia wywarła na świat współczesny, jest olbrzymi”2. Biorąc pod uwagę zasięg i popularność japońskich marek oraz tekstów kultury, można uznać, że kraj ten należy do ważniejszych centrów globalizacjỉ ${ }^{3}$. Oprócz dokonań w przemyśle elektronicznym i motoryzacyjnym Japończycy odnieśli wiele sukcesów na polu szeroko rozumianej kultury. Jedną z nich jest ekspansja kulinarna, czego dowodem sa liczne restauracje inspirowane tamtejszą kuchnią. Światowe uznanie zyskali również japońscy twórcy, jak choćby Akira Kurosawa, Haruki Murakami i Osamu Tezuka. Do najbardziej rozpoznawalnych towarów eksportowych można także zaliczyć mangę, anime i muzykę J-pop. Dla autora Usagiego Yojimbo, urodzonego w Kioto w 1953 r., lecz wychowanego na Hawajach, nie bez znaczenia okazał się wpływ m.in. mangi i kina japońskiego, do których miał łatwy dostęp z uwagi na pochodzenie rodziców oraz swoistą wielokulturowość najmłodszego ze stanów USA.

W młodości Sakai oglądał filmy m.in. Kurosawy (z aktorem Toshirō Mifunem w roli głównej) oraz Hiroshiego Inagakiego. Miał także styczność z mangami Tezuki i Tatsua Yoshidy. Nie powinny zatem dziwić liczne odniesienia do twórczości japońskich reżyserów czy twórców mang. Najbardziej oczywiste jest nawiązanie do filmu Kurosawy z 1961 r. pt. Straż przybocżna. Oryginalny tytuł, Yojimbo, odnosi się do zlecenia, jakie główny bohater, były samuraj, początkowo przyjmuje po przybyciu do miasteczka, w którym dwie zwaśnione rodziny walczą o wpływy. Podejmuje się pracy ochroniarza jednej ze stron, po czym porzuca ja w momencie, gdy doprowadza do starcia pomiędzy oboma skonfliktowanymi rodami. Ma nadzieję, że nawzajem się zneutralizuja, dzięki czemu w miasteczku zapanuje spokój. Jednak zanim do tego dojdzie, będzie musiał stawić czoła niejednej przeszkodzie. Były samuraj Kurosawy wykazuje się dużą siłą fizyczną jak również sprawnością umysłowa. Nie kierują nim pobudki czysto merkantylne, lecz troska o ład społeczny. Choć jest sprawnym rzemieślnikiem śmierci, ceni życie ludzkie i jest zdolny do okazywania łaski swoim przeciwnikom: „Warto żyć, nawet jeśli się jest biednym”4 - mówi najemnikowi, któremu daruje życie. Podobnie jest w przypadku głównej postaci serii Usagi Yojimbo. Usagi dba o dobro innych i pomaga bezbronnym, nie oczekując za to gratyfikacji finansowej. Kierując się zasadami bushidō, unika niepotrzebnego rozlewu krwi. Zawsze też stara się dotrzymać danego słowa. Świat Usagiego Yojimbo jest również podobny do świata przedstawionego w Strasy praybocznej pod względem warstwy wizualnej. Sakai czerpie z twórczości Kurosawy, w szczególności ze scen walk oraz scenerii. Fakt, że komiks

\footnotetext{
2 K.G. Henshall, Historia Japonii, tłum. K. Wiśniewska, Warszawa 2011, s. 13.

3 Zob. K. Iwabuchi, Recentering Globalization: Popular Culture and Japanese Transnationalism, Durham 2002.

4 Strażprzybocżna, reż. A. Kurosawa, 1961.
} 
jest w głównej mierze czarno-biały, również można odczytać jako ukłon w stronę twórczości japońskich autorów. Jest to szczególnie wyraźne, jeśli wziąć pod uwage fakt, że powodowany względami finansowymi brak koloru (jak już wspomnieliśmy Albedo Anthropomorphics ukazał się nakładem własnym Gallaciego) utrzymał się długo po tym, jak komiksy o Usagim zmieniły wydawcę.

Najważniejszą inspiracją dla głównej postaci serii Usagi Yojimbo było życie Musashiego Miyamoto ${ }^{5}$, prawdopodobnie urodzonego w 1584 i zmarłego 13 czerwca 1645 r. Ten siedemnastowieczny ronin wpisał się w kulturę Japonii m.in. jako niepokonany mistrz miecza. Miyamoto był również artysta, pisarzem i filozofem, co czyniło go prawdziwym człowiekiem renesansu. Sakai widział w nim duży potencjał jako źródło inspiracji do swoich komiksów. Jednak zupełnie przypadkowo wpadł na pomysł wykorzystania królika zamiast postaci ludzkiej. Sakai wielokrotnie wspominał w wywiadach o genezie powstania Usagiego: pewnego dnia, jak twierdzi autor, przypadkiem naszkicował królika ze związanymi uszami ${ }^{6}$. Pomysł wydał mu się na tyle ciekawy, że postanowił z niego skorzystać. Choć antropomorficzne zwierzęta nie były niczym nowym w amerykańskich czy japońskich komiksach, to połączenie królika i ronina było czymś oryginalnym. Nadawało to również bardziej uniwersalny charakter głównej postaci, co z pewnością wpłynęło pozytywnie na odbiór komiksu.

Należy równiė̇ wspomnieć o znaczeniu amerykańskiej kultury popularnej, z której autor Usagiego Yojimbo czerpie garściami. Jako sansei ze strony ojca oraz nisei ze strony matki ${ }^{7}$ Sakai z dużą sprawnością porusza się po kulturze USA i stosuje konwencje zachodniego komiksu. Według Maxa Allana Collinsa twórczość Sakaiego przywodzi „na myśl klasyczne komiksy, których bohaterowie: Dick Tracy, Mała Sierotka Annie czy Wash Tubbs - gdyby na chwilę zapomnieć o ich wyglądzie - mogliby spokojnie wziąć udział w prawdziwych przygodach kryminalnych" "Ze względu na humor i ciekawe przygody Collins zauważa również podobieństwo m.in. do serii o Sknerusie McKwaczu, którego autorem był Carl Barks ${ }^{9}$. Jako źródło inspira-

5 S. Sakai, Interview with Stan Sakai: The Artist and his Samurai (wywiad przepr. D. Hustic), http:// www.body-pixel.com/2010/12/29/interview-with-stan-sakai-the-artist-and-his-samurai/ (dostęp: 5.05.2019).

6 S. Sakai, Pewnego dnia narysowatem królika samuraja (wywiad przepr. M. Frenkiel), http://malopolskie.naszemiasto.pl/artykul/pewnego-dnia-narysowalem-krolika-samuraja,222695,art,t,id, tm.html (dostęp: 5.05.2019).

7 Termin sansei jest używany w odniesieniu do Amerykanów pochodzenia japońskiego, którzy są trzecim pokoleniem żyjącym w Stanach Zjednoczonych czy mającym amerykańskie obywatelstwo. Innymi słowy - osoby sansei są dziećmi nisei, tj. drugiego pokolenia imigrantów do USA, i wnukami issei, tj. pierwszego pokolenia. Przypadek Sakaiego jest swoisty, aczkolwiek zdecydowanie można powiedzieć, że jest trzecim pokoleniem z uwagi na wczesny wiek powrotu do Stanów Zjednoczonych (miał wtedy 2 lata).

8 M.A. Collins, Praypadek Usagiego Yojimbo [w:] S. Sakai, Usagi Yojimbo Saga. Ksiega 2, tłum. J. Grzędowicz, Warszawa 2019, s. 438.

I Ibidem. 
cji Sakai dodatkowo wymienia Sergio Aragonésa, twórcę Groo the Wanderer (co ciekawe, postać przypominająca głównego bohatera, Groo, pojawia się w Usagim Yojimbo w historii o pierwszym spotkaniu Usagiego z Tomoe i młodym Noriyukim ${ }^{10}$ ).

Przez ponad 30 lat obecności na rynku wydawniczym Usagi Yojimbo czterokrotnie zmieniał wydawcę. Po publikacji we wspomnianej już antologii Albedo Athropomorphics pojawił się w antologii wydanej przez wydawnictwo Fantagraphics. To właśnie tam Usagi otrzymał pierwszą swoją serię, w ramach której ukazało się 38 regularnych zeszytów oraz 4 wydania specjalne, w tym 3 kolorowe. Druga, licząca 16 zeszytów seria przygód Usagiego ukazała się nakładem wydawnictwa Mirage Studios, znanego głównie z serii Teenage Mutant Ninja Turtles. Następnie zadomowił się w wydawnictwie Dark Horse. Trzecia seria, obejmująca 165 zeszytów, kontynuowała wątki rozpoczęte w poprzednich wydawnictwach. Dzięki temu Usagi Yojimbo oparł się panującej wśród wydawnictw głównego nurtu modzie na ustanawianie na nowo chronologii wydawanych przez nie serii.

W 35. rocznicę Usagi Yojimbo przeszedł z wydawnictwa Dark Horse, z którym był związany od 1997 r., do IDW ${ }^{11}$. Oprócz zmiany wydawcy, jak zapowiada Sakai, na stałe zmieni się również kolorystyka komiksu - seria ma być wydawana wyłącznie w kolorze, co nie wydaje się znaczące z punktu widzenia warstwy fabularnej, lecz niewatpliwie ma wpływ na lekturę, albowiem komiks czarno-biały wywołuje nieco inne skojarzenia i emocje niż komiks w kolorze. Jak pisze Justyna Czaja: „kolor może być jednym z ważniejszych elementów warstwy ikonicznej. Zwykle wzbogaca on wizualną stronę utworu, nierzadko pełni funkcję dramaturgiczną, buduje dodatkowe sensy, wpływa na określony odbiór konkretnych scen"12. W przypadku serii Usagiego Yojimbo kolor nadaje jej głębię i ekspresję. Niewątpliwie kolejne przygody Usagiego nadal będą elektryzowały fanów, o ile Sakai pozostanie wierny swojemu stylowi oraz sposobowi budowania fabuły.

\section{Zwierzę, fala czy samuraj? O wartościach i kodeksie bushidō}

Po przywróceniu szogunatu klasa samurajska utraciła swój status. Niektórzy samuraje przekwalifikowali się na urzędników i zarządców ${ }^{13}$, inni zaś stawali się roninami ${ }^{14}$, tj. samurajami bez pana. Podejmowali się różnych czynności, np. służyli

10 S. Sakai, Usagi Yojimbo Book 1: The Ronin, Seattle 2007, s. 25.

11 Warto odnotować, że seria Usagi Yojimbo dzieli 35. rocznicę z Wojownicsymi Żótwiami Ninja, którzy często pojawiają się u boku Usagiego.

12 J. Czaja, Kolory i ich funkecja w powieści graficznej Zaduszki Rutu Modan [w:] Komiks. Wokót warstwy wizualnej, red. J. Czaja, M. Traczyk, Poznań 2016, s. 167.

13 K.G. Henshall, Historia Japonii..., s. 76.

14 Dosłowne tłumaczenie to „człowiek fala”. 
jako ochroniarze do wynajęcia. Jolanta Tubielewicz zauważa, że roninowie nie cieszyli się dobrą sławą i traktowano ich jak wyrzutki społeczeństwa, których nawet chłopi mogli przepędzić ze wsi ${ }^{15}$. Nie mieli praw do zakładania własnych osad czy wstępowania do służby. Takie właśnie podejście do roninów często widoczne jest w Usagim Yojimbo.

Według Henshalla „to w tym okresie, gdy samuraje stawali się niepotrzebni, pojawił się najdoskonalszy wyraz samurajskich ideałów, bushidō (droga wojownika)" ${ }^{\prime 16}$. Jeden z ważniejszych opisów bushidō pochodzi od Sokō Yamagi, który „podkreślał takie jego aspekty, jak lojalność i samodyscyplina, oraz znaczenie studiów i uprawiania sztuki dla wszechstronnego rozwoju człowieka" ${ }^{17}$. Samuraj miał być strażnikiem moralności, co wymagało od niego interwencji i wymierzania kar, aby pilnować ładu społecznego.

Usagi stoi właśnie na pogranczu dwóch dróg wojownika: ronina i podażającego bushidō samuraja. Z jednej strony jest pogardzanym przez społeczeństwo roninem, odmawia dokonania junshi-samobójstwa poprzez wierność - i postanawia pomścić śmierć swojego pana. Przemierza więc Wyspy Japońskie od osady do osady jako pielgrzymujący wojownik, poszukując przygód i okazji do pomocy potrzebującym. Z drugiej strony Usagi podczas wędrówek pozostaje w zgodzie z bushidō. Co więcej, odmawia zdjęcia barw pana Mifune, jakby cały czas był u niego na służbie; we własnym mniemaniu wciąż pozostaje samurajem.

Usagi staje się roninem działającym zgodnie z kodeksem bushidō, co nie jest niczym niezwykłym, jednakże w świecie przedstawionym komiksu stanowi to pewien ewenement. W dziele Sakaiego roninowie sa bowiem najpopularniejszymi przeciwnikami - rabują wioski, napadają na podróżnych czy zaciagaja się na służbę u spiskujących możnowładców. To dawni samuraje, którzy po utracie panów czy pozycji zatracili drogę i wstąili na ścieżkę przestępstwa. Właśnie w opozycji do nich zostaje przedstawiony Usagi. Choć sam jest roninem, postępuje szlachetnie, staje w obronie słabszych, zaś do przemocy ucieka się jedynie w ostateczności.

Przykładem takiego zachowania może być opowieść Kreggi ${ }^{18}$, w której grupa bandytów atakuje rodzinną wioskę Usagiego. Nie dość, że dopuszczają się grabieży i zastraszają mieszkańców, to jeszcze porywają syna wójta, dawnego przyjaciela Usagiego. Choć wójt Kenji mówi Usagiemu wprost, że ten nie znajdzie w wiosce dla siebie miejsca i widać wyraźnie, iż dawna rywalizacja pomiędzy nimi dwoma nie wygasła, na wieść o porwaniu syna swojego dawnego przyjaciela ronin rusza na pomoc. Podczas próby odbicia małego Jotaro Usagi - choć bardziej doświadczony w walce - dostrzega, że właśnie Kenji dowodzi i ani razu nie próbuje przejać kie-

\footnotetext{
15 J. Tubielewicz, Historia Japonii, Wrocław 1984, s. 278-279.

16 K.G. Henshall, Historia Japonii..., s. 77.

7 Ibidem.

18 S. Sakai, Usagi Yojimbo. Kregi, tłum. W. Nowakowski, Warszawa 2005, s. 75-155.
} 
rownictwa nad grupa wypadowa. Usagi dzięki szlachetnemu zachowaniu odzyskuje zaufanie Kenjiego, który ratuje mu życie w krytycznym dla opowieści momencie.

Gdy pod koniec Usagi dowiaduje się, że właśnie on, a nie Kenji jest ojcem Jotaro, postanawia nie burzyć odzyskanej harmonii i choć przybył do wioski, by w niej osiąść, decyduje się powrócić na szlak. Opuszczając wioskę, spotyka Jotaro, który z dziecięcym entuzjazmem oznajmia mu, że tak jak on chce zostać wojownikiem. $\mathrm{Na}$ pożegnanie ronin dzieli się z chłopcem mądrością: „Miecz służy nie tylko do walki (...). Głownia jedynie wtedy się nie tępi, gdy pozostanie w pochwie" ${ }^{\prime 19}$. Te dwa zdania bardzo dobrze podsumowują filozofię Usagiego - nie liczy się jedynie walka, zaś używania miecza należy unikać.

W porównaniu do roninów ukazanych na kartach wielu już tomów przygód o Usagim on sam wydaje się rycerzem bez skazy. Mimo że na co dzień unika przemocy, gdy sytuacja tego wymaga, nie waha się sięgnąc po miecz. Zawsze staje w obronie słabszych i uciśnionych, a przestępcom wymierza sprawiedliwość. W świecie, w którym ronin jest uosobieniem najgorszych możliwych cech, bohater komiksu Sakaiego mimo statusu ronina wciąż pozostaje samurajem.

\section{Jezzyk, historia i kultura}

Seria Usagi Yojimbo może być ciekawym źródłem dla czytelnika chcącego poszerzyć wiedzę z zakresu języka japońskiego, jak również historii i kultury Japonii. Niemal w każdym komiksie pojawiaja się japońskie wyrazy zapisane alfabetem łacińskim. Sakai umiejętnie wplata liczne ciekawostki na temat Kraju Kwitnącej Wiśni, dzięki czemu czytelnicy nie mają poczucia natłoku informacji. Choć sporadycznie pojawiaja się kadry wypełnione dużą ilością tekstu, jak w przypadku historii o bitwie w zatoce Dan-no-ura ${ }^{20}$, ich obecność jest uzasadniona: $z$ jednej strony tekst wspiera przekaz, z drugiej zaś daje czytającym szerszy kontekst historyczny. Również z perspektywy czytelnika nagromadzenie treści o dawnych zwyczajach, wartościach czy wierzeniach, które maja jednocześnie pierwszo- i drugoplanowy charakter, nie wydaje się wymuszone. Sakai pragnie dzielić się wiedzą o Japonii, lecz wiedza ta - w zależności od intencji czytelnika - jest głównie tłem dla przygód głównego bohatera. To sprawia, że czytanie komiksów z Usagim jest zarazem miłym i wzbogacającym doświadczeniem.

Podstawowym językiem Usagiego Yojimbo jest angielski, aczkolwiek autor wplata również japońskie wyrazy. Największą grupę stanowią rzeczowniki, w tym rzeczowniki określające pełnione urzędy i wykonywane zawody lub czynności, np. bonze (duchowny buddyjski), daimyō (książę feudalny) oraz kunoichi (kobieta ninja), natomiast tytułowy bohater jest roninem (samurajem bez pana) i pielgrzymującym

19 Ibidem.

20 S. Sakai, Usagi Yojimbo. Ostrze bogów, tłum. J. Grzędowicz, Warszawa 2003, s. 29-52. 
wojownikiem (shugyōsha). Pojawiają się również rzeczowniki wyrażające pokrewieństwo i tytuły grzecznościowe, np. ojisan (dziadek, z szacunkiem) oraz przyrostki sensei (mistrz) i kun (tytuł grzecznościowy używany w stosunku do chłopców). Wymieniane są nazwy rodzajów białej broni i cięcia, np. jutte (pałka z hakiem), wakizashi (krótki miecz) i ryo kuruma (cięcie wzdłuż bioder). Liczne są także nazwy demonów i istot o nadprzyrodzonych mocach, np. obake (straszydło) i koshi (ośmiogłowy wąż). Przy wielu okazjach czytelnicy widzą Usagiego kosztującego typowe warzywa i potrawy japońskie, w tym daikon (rzodkiew), kabocha (dynia), soba (makaron gryczany), sashimi (surowe plastry pokrojonej ryby) i takoyaki (opiekana ośmiornica). Wymienione sa instrumenty i przedmioty codziennego użytku, tj. furoshiki (chusta do pakowania), kinchaku (worek na pieniądze), waraji (sandały ze słomy) i shakuhachi (bambusowy flet). Pojawiają się również jednostki miary czasu i odległości, np. godzina tygrysa (od trzeciej do piątej rano) i ri (w przybliżeniu 3,9 km), jak również jednostki monetarne, np. ryō. W odcinku zatytułowanym $S h i^{21}$ Sakai sięga do gry słownej. Tytułowe $s h i$ w znaczeniu liczebnikowym oznacza cztery, natomiast w innym kontekście może oznaczać śmierć. Kilkukrotnie również pojawia się zwrot abayo (na razie). Wspomniano także znane przysłowie japońskie nawiązujące do trzech niebezpiecznych żywiołów występujących w naturze i jednego w domu, tj. trzęsienia ziemi, gromu, ognia i ojca (jishin, kaminari, kaji, oyaji).

Historia jest ważnym elementem komiksów Sakaiego, który odnosi się do prawdziwych wydarzeń i postaci. Jako przykład może posłużyć prolog do tomu Ostrze bogów i przedstawiona w nim bitwa pomiędzy rodami Taira i Minamoto, która odbyła się w zatoce Dan-no-ura w XII wieku. W wyniku tej bitwy śmierć poniósł młody cesarz Antoku z rodu Taira, który wraz z regentką umyślnie wskoczył do wody, aby uniknać dostania się w ręce wrogów. Wraz z nimi utonął również święty miecz, co staje się zaczątkiem właściwej opowieści toczącej się w XVII stuleciu.

Kolejnym przykładem obecności historii w Usagim Yojimbo jest nawiązanie do walki szogunatu z religia chrześcijańską w pierwszej połowie XVII wieku, której przyczyną była obawa przed destabilizacją ${ }^{22}$. Jedna z metod służących do wykrywania chrześcijan polegała na bezczeszczeniu symboli religijnych. Ci, którzy odmawiali wykonania rozkazu nadepnięcia na fumi-e (tj. obrazek z podobizną Chrystusa lub Maryi), ujawniali tym samym swoją przynależność do wspólnoty chrześcijańskiej.

Sakai podejmuje również tematykę sprawiedliwości, ukazując w interesujący sposób realia panujące w Japonii w okresie Edo. W przypadku morderstw nie można było przeprowadzać sekcji zwłok. Po aresztowaniu i przesłuchaniu podejrzanych zaprowadzano do urzędnika, który wydawał wyroki na dziedzińcu wypełnionym białymi kamykami (shirasu $)^{23}$. Za najpoważniejsze przestępstwa skazywano na karę

\footnotetext{
21 S. Sakai, Usagi Yojimbo. Cienie śmierci, tłum. J. Grzędowicz, Warszawa 2002, s. 74-128.

22 S. Sakai, Usagi Yojimbo: The Hidden \#1, Milwaukie 2018, s. 21.

23 S. Sakai, Usagi Yojimbo Saga Book. 1, Milwaukie 2014, s. 475.
} 
śmierci. Wyroki te były wykonywane przez eta, tj. osoby należące do najniższej warstwy społecznej.

Oprócz wydarzeń historycznych Sakai ukazuje różne japońskie praktyki i zwyczaje. Jednym z nich jest stawianie i ubieranie posagów Jizō, opiekuna zmarłych i nienarodzonych dzieci. Według wierzeń buddyjskich chroni on dzieci przed demonami, dlatego rodzice dzieci zmarłych przedwcześnie modlą się do niego. Komiks, w którym pojawia się Jizō, jest szczególny ze względu na sposób przedstawienia fabuły oraz rolę, jaką odgrywa pewien przydrożny posag. Wszystkie kadry są tej samej wielkości i kompozycji - w tle rozciaga się górzysty krajobraz, na drugim planie widać drogę, natomiast na pierwszym planie od trzeciego aż do ostatniego kadru widnieje posą Jizō. Jego umiejscowienie nie jest przypadkowe - staje na uboczu, dlatego też znajduje się blisko prawej linii kadrów. Wydawałoby się, że jest jedynie niemym świadkiem wydarzeń toczących się na drodze. Z jednej strony nie mogłoby być inaczej, ponieważ nie należy do świata żywych. Jednakże być może to on przyciagnął Usagiego, dzięki czemu droga, przy której stoi, znów staje się bezpieczna. Nie sposób uniknąć porównania Usagiego i Jizō, gdyż obaj pełnią funkcję opiekunów, stojąc na straży bezbronnych i potrzebujących.

Sakai wplata też w fabułę różne tradycje, m.in. święto Tanabata ${ }^{24}$, które zyskało na popularności w okresie Edo ${ }^{25}$. Według podań parę kochanków - Shokujo i Kengyu - rozdzielono rzeką Amanogawa. Jedynie raz do roku mogli się spotkać za pomocą srok, które tworzyły most ze skrzydeł, umożliwiając kochankom przejście. Przy okazji tego święta pisano wiersze miłosne na kawałkach papieru przyczepionych do wstążki (tanzaku), a następnie wieszano je na gałązkach bambusa.

W Usagim Yojimbo znajdziemy także odniesienie do teatru kabuki, który powstał na początku XVII wieku. W odcinku zatytułowanym Morderstwo szpila do włosów. Tajemnica inspektora Ishidy ${ }^{26}$ pojawia się trupa artystyczna ze spektaklem Narukami. Do zespołu należą Goku i jego siostra. Wybór spektaklu z pewnością nie jest przypadkowy, biorąc pod uwage dalszą fabułę. Akcja komiksu toczy się po wprowadzonym w 1629 r. zakazie pojawiania się kobiet na scenie. Jak pisze Henshall: „Aktorki wczesnego teatru kabuki trudno było odróżnić od prostytutek, a przedstawienia często przeradzały się w orgie. Zaalarmowany szogun zakazał kobietom występów scenicznych" ${ }^{27}$. Role kobiece przejęli męscy aktorzy, zwani onnagata ${ }^{28}$. Takim aktorem jest Goku, który w przebraniu kobiety najpierw uwodzi morderców swojej rodziny, a następnie rozprawia się $z$ nimi.

24 Ibidem, s. 375.

25 H. Shirane, Japan and the Culture of the Four Seasons: Nature, Literature, and the Arts, New York 2013, s. 159.

26 S. Sakai, Usagi Yojimbo saga. Ksiega 2..., s. 513.

27 K.G. Henshall, Historia Japonii..., s. 81.

28 S. Sakai, Usagi Yojimbo saga. Ksiega 2..., s. 639. 
Pozostając przy temacie rozrywki i przyjemności, Sakai również przedstawia świat kurtyzan. Jak pisze autor: „Nie należy mylić oiran [kurtyzana] z gejszami (...). Te ostatnie kształcono w tańcu, śpiewie, grze na instrumentach i sztuce konwersacji. Gejsze nadal istnieją, jednak oiran, jakkolwiek portretowane w niezliczonych filmach i w sztuce, znikły bezpowrotnie"29. W okresie Edo kurtyzany oferowały swoje usługi najbogatszym i najbardziej wpływowym osobom. Niekiedy owocem ich zbliżeń były dzieci, które mogły stanowić zagrożenie dla interesów rodzin klientów. W komiksie Sakaiego takim dzieckiem okazuje się potomek kurtyzany i jej sponsora, lecz dzięki Usagiemu młody Kotaro znajduje bezpieczny dom.

W przygodach bohaterskiego ronina nie zabrakło również ciekawostek na temat produkcji m.in. mieczy. Sakai rekonstruuje proces ich wyrabiania w historii pt. Daisho ${ }^{30}$, ukazując przy tym znaczenie mieczy zarówno dla tych, którzy je tworzyli, jak i tych, którzy później nimi władali. Nie dziwi fakt, że do wyprodukowania broni o najwyższej jakości potrzebowano odpowiednich materiałów i dużego nakładu pracy. Konieczne były również kunszt i poświęcenie. Najlepsi płatnerzy wkładali swoje dusze w kute przez siebie wyroby. Miecze, które przeszły kontrole jakości, czekały na godnego właściciela. Dla samuraja jego miecze również miały szczególne znaczenie, a ich utratę można było porównać do utraty duszy. Gdy daisho Usagiego zostaje zawłaszczone przez dowódcę bandy rozbójników, czytelnicy nie mają wattpliwości co do determinacji Usagiego do ich odzyskania.

Sakai nie zapomniał także o podstawowych aspektach życia, takich jak przygotowanie żywności. Pokazuje, jak robiono m.in. sos sojowy i listki nori. Podczas spotkania z mistrzem warzenia shoyu Usagi przyznaje: „Całe życie używałam shoyu, ale nigdy się nie zastanawiałem, jak powstaje" 31 . Produkcja sosu sojowego nie wydaje się nadzwyczaj skomplikowana, jednakże trwała stosunkowo długo z uwagi na proces fermentacji. Podziw mogły wzbudzić m.in. liczba i pojemność wykorzystywanych beczek. Ciekawostką może być fakt, że smak shoyu również zależy od mikroorganizmów znajdujących się w warzelni. Ta historia jest ukłonem w stronę tradycji i stanowi przestroge przed pochopnymi zmianami, szczególnie tymi motywowanymi zwiększeniem i usprawnieniem produkcji. Produkcja nori była mniej skomplikowana i trwała zaledwie kilka dni ${ }^{32}$. Sakai opisuje dzieci chodzace na szczudłach w sandałach geta podczas zbierania wodorostów, co miało umożliwić im chodzenie w wodzie i zebranie wodorostów pływających na powierzchni. Dorośli zaś korzystali z łódek i specjalnych tyczek. W obu przypadkach proces produkcji stanowi tło do historii o zwaśnionych rodzinach, lecz z punktu widzenia czytelnika poszukujacego wiedzy o Japonii obie historie mają duży walor informacyjny. Rola Usagiego

\footnotetext{
29 Ibidem.

30 Tytuł komiksu odnosi się do kompletu dwóch mieczy, który stanowił wyposażenie samuraja.

31 S. Sakai, Usagi Yojimbo. Dwieście posażkóm Jizo, tłum. J. Grzędowicz, Warszawa 2016, s. 142.

32 S. Sakai, Usagi Yojimbo. Pomiędzy życiem a śmiercia, tłum. J. Grzędowicz, Warszawa 2002, s. 9-28.
} 
sprowadza się do ochrony jednej ze stron i znalezienia sposobu na rozwiązanie panującego sporu.

Komiksy Sakaiego czerpią również z mitologii japońskiej. Jednym z nich jest komiks o Izanagi i Izanami ${ }^{33}$, stanowiący prolog do tomu Ostrze bogón ${ }^{34}$. Potomkiem tej pary jest m.in. bóg ognia Kagutsuchi. Jego narodziny kończą się śmiertelnie dla Izanami. Izanagi postanawia odzyskać ukochaną i udaje się do krainy zmarłych Yomi. Odnajduje małżonkę, lecz okazuje się, że ta zupełnie się zmieniła. Przerażony Izanagi ucieka z Yomi, zostawiając rozwścieczoną Izanami. Po powrocie do świata żywych Izanagi oddaje się kapieli w celu oczyszczenia swojego ciała. $Z$ wody wyłania się m.in. bogini słońca Amaterasu i bóg morskiego przestworu Susano-o. Ta historia jest istotna z punktu widzenia dalszych przygód Usagiego, który przypadkowo wchodzi w posiadanie legendarnego miecza podarowanego Amaterasu przez Susano-o. Choć wygląda niepozornie, jest niezwykle cenny, gdyż składa się na regalia cesarskie. Usagi zobowiązuje się ukryć miecz, świadomy ewentualnych konsekwencji, gdyby miecz wpadł w niepowołane ręce.

Do mitologii odwołuje się też komiks o Namazu ${ }^{35}$. Potwór Namazu to wielki sum mieszkający pod ziemia. Jego ruchy powodują trzęsienia ziemi, dlatego został uwięziony pod wielkim kamieniem przez Kashimę, boga piorunów. Zadaniem Usagiego i jego towarzyszy jest dopilnowanie, aby wyszczerbiona część kamienia przytrzymująca potwora nie wpadła w niepożądane ręce. W razie niepowodzenia skutki byłyby katastrofalne - Japonię nawiedziłyby trzęsienia ziemi, powodując liczne zniszczenia.

W 25. rocznicę Usagiego Yojimbo wydawnictwo Dark Horse wydało Yokai, który wyróżnia się na tle innych m.in. rozległością fabuły, techniką i kolorystyką ${ }^{36}$. Jest zdecydowanie dłuższy od wcześniejszych komiksów o Usagim, dzięki czemu historia jest bardziej rozwinięta. Wykończenie akwarelami wpływa na dynamizm oraz ekspresyjność. Dzięki dodawaniu warstw uzyskano efekt głębi poprzez przenikanie się kolorów, natomiast samo zastosowanie koloru uwydatniło i wzbogaciło akcję oraz bohaterów. Inspiracją do tego komiksu była nocna parada demonów, odbywająca się raz w roku latem. Spotkanie z yōkai nie należy do najprzyjemniejszych czy najbezpieczniejszych, o czym przekonuje się Usagi, gdy postanawia pomóc zrozpaczonej kobiecie poszukującej swojej córki. Usagi wkracza w barwny świat duchów, demonów i potworów, całkowicie nieświadomy czyhających na niego zagrożeń.

33 W przekładzie Historii Japonii autorstwa Henshalla Izanagi i Izanami przetłumaczono w następujący sposób: Mąż, który wabi oraz Niewiasta, która wabi. W tłumaczeniu wydawnictwa Egmont nazwy tych samych bogów przetłumaczono na Ten, który sprowadza i Ta, która sprowadza.

34 S. Sakai, Usagi Yojimbo. Ostrze bogón, tłum. J. Grzędowicz, Warszawa 2003, s. 5-11.

35 S. Sakai, Teenage Mutant Ninja Turtles/Usagi Yojimbo, San Diego 2017.

36 S. Sakai, Usagi Yojimbo: Yokai, Milwaukie 2009. 


\section{Podążając za królikiem, czyli trochę o warstwie wizualnej}

Kolejne tomy komiksów o Usagim rozpoczynają się od wstępów autorstwa wielu znamienitych twórców komiksowych, takich jak Stan Lee, Alejandro Jodorowsky czy Will Eisner. Autorzy często porównują w nich komiksy o Usagim do innych tekstów kultury - filmów fabularnych czy animowanych. William Stout, artysta pracujący przy takich filmach, jak Park Jurajski, posunął się w swoich porównaniach tak daleko, by stwierdzić, że „Usagi Yojimbo to Królik Bugs w filmie Kurosawy”37. Porównanie wydaje się oczywiste - w obu przypadkach bohaterami są zantropomorfizowane zwierzęta, doświadczające przeróżnych przygód. Na tym jednak podobieństwa się kończą.

Jedną z ważniejszych różnic pomiędzy Królikiem Bugsem a Usagim Yojimbem jest warstwa wizualna, a w szczególności tło i jego elementy. W przypadku komiksów o Kaczorze Donaldzie i filmów animowanych wytwórni Warner Bros tło nie jest umiejscowione w konkretnej epoce historycznej. Służy ono umiejscowieniu historii w czasie i przestrzeni, lecz nie stanowi celowego kontekstu kulturowo-historycznego. W komiksach o Usagim kontekst historyczny jest bardzo wyraźny, a warstwa wizualna szczególnie go podkreśla. Budynki, stroje przechodniów, uzbrojenie czy nawet roślinność - wszystkie te elementy są nieodłączną częścią konkretnego kontekstu kulturowego, do jakiego Sakai chce nawiązać, zaś umowność widoczna jest w przedstawionych postaciach, co omówimy później. Tymczasem akcja komiksów o Kaczorze Donaldzie, mimo że umiejscowiona w kulturze, w której powstały, mogłaby się toczyć właściwie wszędzie na świecie.

Tło w komiksach o przygodach Usagiego Yojimbo odgrywa ważną rolę. Dzięki dokładnie odwzorowanej architekturze oraz szczegółowym strojom i uzbrojeniu czytelnik ma okazję poznać kulturę siedemnastowiecznej Japonii. Zastosowany przez Sakaiego zabieg pomaga w umiejscowieniu historii w czasie i przestrzeni, nadaje jej kontekstu, a do tego dzięki bogactwu historycznie dokładnych szczegółów poniekąd uwiarygadnia opowiadaną historię. Komiks jest doskonałym medium do pokazania tego bogactwa. Zamiast opisywać poszczególne elementy architektoniczne każdego z budynków, szczegóły ubiorów i sposoby ich noszenia czy charakterystyczne dla Wysp Japońskich krajobrazy, Sakai jest w stanie pokazać je czytelnikowi niejako mimochodem. Tym samym nie potrzebuje wdawać się w długie i szczegó-

37 S. Sakai, Usagi Yojimbo. Cienie..., s. 2. W oryginale Stout pisze: „Usagi Yojimbo is Carl Barks meets Akira Kurosawa - with more nudity”, nawiązując tym samym do słynnego z komiksów o Kaczorze Donaldzie rysownika Carla Barksa, twórcy takich postaci, jak Sknerus McKwacz. Niestety, w Polsce nie cieszy się on taką samą sława jak w Stanach Zjednoczonych, przez co tłumacz Jarosław Grzędowicz postanowił zastosować ekwiwalent dynamiczny i odnieść się do postaci bliższej polskiemu czytelnikowi, choć wciąż znajdującej się w kręgu komiksów i filmów animowanych. 
łowe opisy poszczególnych elementów kulturowych, jakie byłyby potrzebne, gdyby Usagi Yojimbo był tekstem jedynie pisanym.

Nie uprawnia to jednak do generalizacji, że każdy komiks zawierający elementy kulturowe danego kraju będzie lepszym przedstawieniem owej kultury niż tekst pisany. W przypadku Usagiego Yojimbo kolosalne znaczenie ma dbałość o szczegóły zastosowana przez samego autora. Sakai chlubi się dokładnością w odtwarzaniu rzeczywistych miejsc, przedmiotów, a nawet wydarzeń. Jako dowód może służyć anegdota przytoczona przez niego podczas spotkania z czytelnikami w Portland, gdzie opowiadał o procesie tworzenia swojego komiksu ${ }^{38}$. Wspomniał o drobnej pomyłce, jakiej dopuścił się w historii pt. Zagadka maski demona ${ }^{39}$, gdzie Usagi oraz inspektor Koji rozgrywają partię gry Go. Gra, którą Sakai pamiętał z dzieciństwa, w rzeczywistości była grą Gomoku, która także toczy się na planszy do Go. Gdy błąd został mu wskazany, Sakai postanowił zgłębić zagadnienie, jakim jest gra w Go. Skontaktował się z Amerykańskim Stowarzyszeniem Go i uznał, że powinien poprawić swój błąd w wydaniu zbiorczym komiksów o Usagim. Przerysował więc układ planszy widoczny w Zagadce maski demona i umieścił na niej rozgrywkę dwóch mistrzów Go pochodzącą z 1856 r.

Choć element ten pozostaje w tle i nie wnosi wiele do przebiegu akcji, wzbogaca całość komiksu, jednocześnie uwiarygodniając przedstawioną w nim historię. Dbałość o szczegóły ze strony autora dodaje komiksowi autentyczności. Dzięki takim drobiazgom i chęci Sakaiego do naprawy swoich pomyłek czytelnik może zaufać, że otrzymuje możliwie najdokładniejsze odwzorowanie realiów, w jakich umieszczony jest komiks. Efekt ten zostaje wzmocniony także przez pojedyncze zeszyty, w których elementy kulturowe zwykle pozostające w tle są wysunięte na pierwszy plan, a nawet stają się tematami poszczególnych historii.

Dobrym przykładem takiego podejścia jest omawiana wcześniej historia Kaisō z tomu Pomiędy życiem a śmierciaq ${ }^{40}$, w której Usagi trafia do wioski hodowców wodorostów. Część tej opowieści Sakai spędza na dość szczegółowym przedstawieniu sposobu, w jaki uprawiane były wodorosty. Za pomocą kilku rysunków dokładnie omawia on poszczególne aspekty uprawy. Dopiero po szczegółowym opisaniu sposobu uprawy wodorostów przechodzi do historii konfliktu pomiędzy dwiema konkurującymi osadami. Staje się ona poniekąd tłem dla prawdziwego celu powstania tej opowieści, czyli przedstawienia sposobu uprawy wodorostów.

Podobny zabieg autor stosuje w podzielonej na trzy części opowieści Drieje pewnego latawca ${ }^{41}$. Pierwsza z nich jest poświęcona szczegółowemu opisowi procesu budowy latawca odako. Jej narratorem jest konstruktor japońskich latawców

38 S. Sakai, Stan Sakai on Usagi Yojimbo and Drawing (wystapienie w Portland Museum of Art), https://www.youtube.com/watch?v=oTMKqFEwSPA (dostęp: 21.05.2019).

39) S. Sakai, Usagi Yojimbo. Maska demona, tłum. J. Grzędowicz, Warszawa 2004, s. 77-148.

40 S. Sakai, Usagi Yojimbo. Pomiedzy syciem..., s. 9-28.

41 S. Sakai, Usagi Yojimbo. Samotny cap i koźle, tłum. W. Nowakowski, Wrocław 2005, s. 25-44. 
Tatsusaburo, który metodycznie opisuje proces ich budowy. Poszczególne etapy od ścinania bambusa jesiena, poprzez produkcję papieru, po malowanie latawca są nie tylko omówione przez narratora, lecz także ukazane w kolejnych kadrach. W ten sposób czytelnik ma przed sobą dokładny opis całego procesu oraz ilustrację wszystkich kroków, które razem tworzą swoistą instrukcję budowy latawca odako. Druga, pozornie niezwiązana z poprzednią część dotyczy oszukujących w grze w kości szulerów. Sam Sakai przyznaje, że najtrudniejszym zadaniem było zbadanie, w jaki sposób wówczas oszukiwano w tej grze ${ }^{42}$. Dopiero pod koniec zawiązuje się akcja, która w części trzeciej łączy ze sobą dwie poprzednie. Usagi przyłapuje szulerów na oszustwie i ich demaskuje, ściagając na siebie ich gniew zostaje przegoniony $z$ osady i ucieka uczepiony latawca zbudowanego na początku opowieści.

W Driejach pewnego latawca Sakai rezygnuje z przygodowego charakteru komiksu na rzecz aspektu edukacyjnego. Głównym celem opowieści staje się przekazanie wiedzy na temat kultury feudalnej Japonii, a nie przygody głównego bohatera, które tym razem stanowią zaledwie tło, klamrę spinającą dwie na pozór oddzielne historie.

Po analizie powyższych przykładów można dojść do wniosku, że kiedy Jarosław Grzędowicz, tłumacząc wstęp Williama Stouta, opisywał przygody Usagiego jako Królika Bugsa w filmie Kurosawy, położył nacisk na niewłaściwy element. To właśnie pozornie podązające za głównym bohaterem, wypełnione szczegółami tła bardzo często graja pierwsze skrzypce w historiach o Usagim. Stout, a właściwie Grzędowicz, powinien sformułować tezę w sposób odmienny: Usagi Yojimbo to film Kurosawy z udziałem Królika Bugsa. W rzeczywistości bowiem samo tło, czyli film Kurosawy, często staje się najważniejsze, bohater natomiast gra rolę odmienna - staje się kluczem do tła, na którym jest przedstawiony.

\section{Królik-ikona-klucz}

W 1993 r. na rynku amerykańskim ukazała się publikacja Zrozumieć komiks autorstwa Scotta McClouda, komiks-podręcznik opisujący podstawowe pojęcia i swoista gramatykę medium komiksowego, którego sam jest przedstawicielem. W książce tej McCloud przedstawia m.in. koncept cartoonu jako ikony umożliwiającej czytelnikowi przywdzianie maski bohatera, utożsamienie się z nim i łatwiejsze wkroczenie w świat przedstawiony w komiksie. Powołuje się przy tym na takie komiksy, jak Pràygody Tintina belgijskiego rysownika Herge'a, w których uproszczony do cartoonowej formy bohater - tytułowy Tintin doświadcza przygód w szczegółowo narysowanym, realistycznym świecie. Podobne uproszczenie można znaleźć w Maus Arta

42 S. Sakai, National Library Week Event: Stan Sakai, Creator of Usagi Yojimbo, https://aadl.org/ node/370483 (dostęp: 24.05.2019). 
Spiegelmana, historii o Holokauście, w której Żydzi przedstawieni są jako myszy, Polacy jako świnie, zaś Niemcy jako koty. Choć symboliczny wymiar tej ikonizacji jest ewidentny, ma ona także wymiar praktyczny. Dzięki zabiegowi umieszczenia antropomorficznych zwierząt jako bohaterów opowieści czytelnikowi łatwiej jest zrozumieć przerażającą tematykę Holokaustu i utożsamić się z jego ofiarami ${ }^{43}$.

Ten sam zabieg wykorzystuje Sakai w Usagim Yojimbo. Królik samuraj staje się kluczem do przedstawionego w komiksie świata, który - jak wspominaliśmy wcześniej - pełen jest odniesień do historii i kultury Japonii z okresu Edo. Dzięki przedstawieniu głównego bohatera jako ikony, symbolu walecznego ronina, a nie szczegółowo narysowanego człowieka lub wyobrażenia Musashiego Miyamoto, na którego życiu została oparta historia Usagiego, Sakai ułatwia czytelnikowi odnalezienie się w świecie komiksu. McCloud zauważa, że gdyby bohater nie był cartoonem, a szczegółowym odzwierciedleniem istniejącej postaci, czytelnik stałby się zbyt świadom osoby posłańca i nie mógłby skupić się na przekazywanej treści na tyle, by poddać się całkowitej immersji ${ }^{44}$. Przeciwnie, zacząłby odbierać opowieść jako biografię Musashiego Myiamoto lub komiks historyczny, a nie przygodę z bogatym tłem kulturowo-historycznym.

Warto też zwrócić uwagę na fakt, że w przeciwieństwie do komiksu Maus antropomorfizacja postaci w serii Usagi Yojimbo nie ma wyraźnego klucza. W jednym z wywiadów Sakai przyznał, że tytułowy bohater jego serii został królikiem z powodu podobnego brzmienia słowa usagi z imieniem Musashit ${ }^{45}$. Nie ma tu więc powiązania cech typowych dla królików z cechami, jakimi odznacza się główny bohater - Usagi. Jedynym przykładem świadomego wyboru konkretnego zwierzęcia, pod jakim autor przedstawił postać, ze względu na kulturowe znaczenie, jest postać Kitsune. Jest ona lisica, uliczną performerka, która dodatkowo para się kradzieżą kieszonkową. To wyraźne nawiązanie do postaci lisa w kulturze japońskiej (i nie tylko), w której jest on zmiennokształtnym bogiem tricksterem płatającym figle samurajom, bogatym kupcom czy zwykłym chłopom ${ }^{46}$.

Chociaż tradycja literacka sięgająca aż do bajek Ezopa sugeruje czytelnikowi, by dopatrywał się ukrytych znaczeń w doborze zwierząt jako postaci, w przypadku komiksu o Usagim będzie to działanie bezcelowe. Poza wspomnianą Kitsune do tworzenia bohaterów Sakai stosuje raczej perspektywę wizualną, a nie semiotyczną. Sam autor przyznaje, że stworzył postaci, takie jak nosorożec Gen, ponieważ

43 S. McCloud, Zrozumieć komiks, tłum. M. Błażejczyk, Warszawa 2015, s. 29-45.

44 Ibidem, s. 36-37.

45 S. Sakai, Stan Sakai...

46 Ciekawe podejście do dwoistości lisa jako boga-trickstera przedstawia J.H. Wilbur III w The Fox Spirit: The Japanese Trickster?, https://repository.wlu.edu/handle/11021/33389?show=full (dostęp: 29.05.2019). 
dobrze kontrastowały z głównym bohaterem ${ }^{47}$. Nie ma więc klucza służącego do rozszyfrowania ukrytych znaczeń stojących za przypisaniem zwierząt do poszczególnych bohaterów. To raczej postaci są kluczem do świata przedstawionej opowieści i kultury stanowiącej jej podłoże.

\title{
Podsumowanie
}

Seria Usagi Yojimbo jest warta przeczytania zarówno z uwagi na mistrzowski kunszt artystyczno-literacki jej autora, jak i ze względu na bogactwo informacji na temat Japonii z okresu Edo. Choć głównym bohaterem jest królik, co wydawałoby się wskazywać na niski poziom realizmu i ukłon w stronę raczej młodszego czytelnika, Usagi Yojimbo może być doceniony także przez dorosłych fanów komiksu. Sakai inspiruje się historią i kulturą kraju swoich przodków, nadając swoim opowieściom charakter edukacyjny. Mimo że ciekawostki sa jedynie tłem na poziomie fabularnym, ich znaczenie okazuje się kluczowe z punktu widzenia czytelnika szukającego informacji na temat dawnej Japonii. Co więcej, różnorodność informacji o charakterze historyczno-kulturowym sprawia, że Usagi Yojimbo jest odpowiedni dla czytelnika posiadającego zarówno bardziej, jak i mniej zaawansowaną wiedzę na temat Kraju Kwitnącej Wiśni.

\author{
SUMMARY \\ COMICS, CRITTERS, AND KATANAS: \\ USAGI YOJIMBO AND EDO PERIOD JAPAN
}

Stan Sakai's Usagi Yojimbo is an ongoing comic book series devoted to the adventures of Usagi Miyamoto. The eponymous character is a rabbit ronin that wanders the Japanese archipelago. Despite its seeming simplicity, the Usagi Yojimbo series is a true trove of information about Edo period Japan. This article presents different ways in which readers are able to acquire knowledge about Japan from reading Usagi Yojimbo. It focuses on several aspects of the series that present elements of Japanese culture, history, and language. The article also discusses the visual aspects of Sakai's Usagi Yojimbo comics that have an effect on readers' perception of the presented content and influence their learning about Japanese culture.

47 S. Sakai, Diaflogue: Stan Sakai Exclusive Q\&A, http://fantagraphics.com/flog/diaflogue-stan-sakai-exclusive-qa-2/ (dostęp: 19.06.2019). 